\title{
Automobile Noise Control: Circuit and System
}

\author{
Sayel M. Fayyad
}

\begin{abstract}
This paper presents a description and analysis for the control circuit of noise in automobiles in the presence of diesel particulate filter( DPF), this paper aims to construct a control system for controlling the noise of the automobiles produced by the engine and then calculating the transfer function, $T(s)$, that relates the output percent of noise to the input variables that can be represented by the magnitude and shape of tune of the engine sound. Analytical methodology is used here to formulate the transfer function and analyze the system. The response of the control system was calculated by taking the inverse of Laplace function of $\mathrm{Y}(\mathrm{s})$, it is found that the magnitude of the noise is attenuated and has a steady state response with some presented error that is directly depended on the specifications of the DPF such as its dimensions and porosity.
\end{abstract}

Index Terms - Control systems, diesel particulate filters noise control, transmission losses.

\section{INTRODUCTION}

The noise of the diesel engines of automobiles makes what is called now noise pollution this is really considered one of the most hazardous pollutant affected human life and causes many healthy problems. So controlling such problem becomes crucial. Diesel particulate filters (DPF) are used mainly to make emission reduction in automobiles, in addition to this primary role it can be used as noise reduction device.

Diesel Particulate Filters are exhaust after treatment devices that significantly reduce emissions from diesel fueled vehicles and equipment. DPFs typically use a porous ceramic media or cordierite substrate or metallic filter, to physically trap particulate matter (PM) and remove it from the exhaust stream. After it is trapped by the DPF, collected PM is reduced to ash during filter regeneration. Regeneration occurs when the filter element reaches the temperature required for combustion of the PM. "Passive" regeneration occurs when the exhaust gas temperatures are high enough to initiate combustion of the accumulated PM in the DPF, without added fuel, heat or driver action. "Active" regeneration may require driver action and other sources of fuel or heat to raise the DPF temperature sufficiently to combust accumulated PM. Sayel M. Fayyad et al. 2009, constructed a mathematical model to control the noise using porous media with applications to diesel particulate filters. The last models constructed by S. Allam (2005), ignored the transverse velocity of gasses entered the DPF in the present model such effects are considered the results so an

Manuscript received May 2, 2013; revised July 2, 2013.

Sayel M. Fayyad is with Department Of Mechanical Engineering, Faculty Of Engineering Technology, P.O. Box 15008, Jordan, Al-Balqa Applied University Amman-Jordan(e-mail: ssayel@Fet.Edu.jo). enhancement in controlling the noise. The main thing in constructed the noise control system is the location of the DPF because the location plays an important role in both gas emission reduction and noise reduction.[1]-[3].

The frequency of regeneration is determined by the engine's duty cycle, PM emission rate, filter technology and other factors. When using an active filter, it is particularly important to follow the manufacturer's instructions for regeneration. See Fig. 1, also Fig. 2 shows the DPF operation.

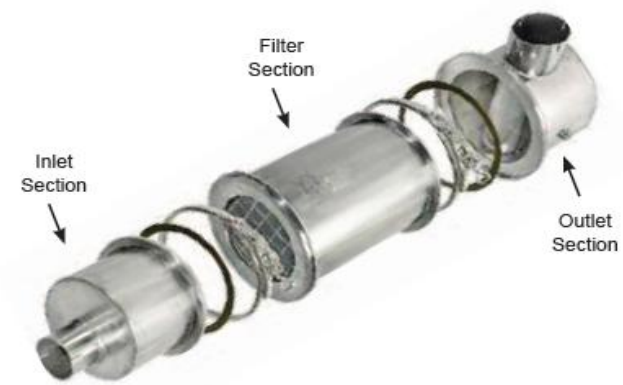

Fig. 1. Diesel particulate filter [1].

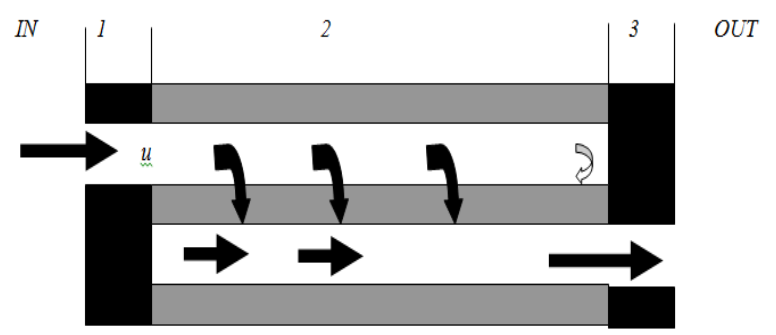

Fig. 2. DPF operation and gasses flow.

Noise is defined as unwanted waves that affects our life and causes uncomfortable conditions, in many cases noise will cause annoyance and discomfort. The noise produced by automobiles may depends of the engine size and type of the vehicle, see Table I.[3], and [4]

TABLE I: AUTOMOBILES NOISE LEVELS

\begin{tabular}{|l|l|}
\hline Type of vehicle & $\begin{array}{l}\text { Sound level } \\
\mathbf{d B}(\mathbf{A})\end{array}$ \\
\hline Personal car & 74 \\
\hline $\begin{array}{l}\text { Bus and truck with total weight below } 3.5 \text { ton with total } \\
\text { weight below } 2 \text { ton }\end{array}$ & 76 \\
\hline with total weight above 2 ton but below 3.5 ton & 77 \\
\hline $\begin{array}{l}\text { Bus with total weight above } 3.5 \text { ton with engine power } \\
\text { below } 150 \mathrm{~kW}\end{array}$ & 78 \\
\hline with engine power $150 \mathrm{~kW}$ or above & 80 \\
\hline $\begin{array}{l}\text { Truck with total weight above } 3.5 \text { ton with engine power } \\
\text { below } 75 \mathrm{~kW}\end{array}$ & 77 \\
\hline with engine power below between $75 \mathrm{~kW}$ and $150 \mathrm{~kW}$ & 78 \\
\hline with engine power above $150 \mathrm{~kW}$ & 80 \\
\hline
\end{tabular}

One of the leading technologies for meeting future particulate matter (PM) emission standards is the diesel particulate filter (DPF). These devices generally consist of a wall-flow type filter positioned in the exhaust stream of a 
diesel vehicle. As the exhaust gases pass through the system, particulate emissions are collected and stored. Because the volume of diesel particulates collected by the system will eventually fill up and even plug the filter, a method for controlling trapped particulate matter and regenerating the filter is needed. Diesel particulate filter is a superior system in the reduction of particulate matters because it can lead to a reduction of about $70 \%$ of the PM. It contains a large numbers of thin tubes or cavities with a diameter of about (1-2 mm), and (0.15-0.5 cm) length. [5]-[8].

There are many types of DPF's such as: electric heater type, burner type (ceramic filter), and fuel additive type; the latter type is a honey-comb ceramic. The honey-comb type constitutes an additive supply and an electronic system. In this type $\mathrm{Fe}$ is used as an additive whereby iron oxide is formed which reacts with carbon and then it is converted to iron. The DPF is connected on the exhaust pipe, hence noise and vibration characteristics of exhaust system are changed and consequently affect the performance of the engine by developing back pressure, change temperature and velocity of the exhaust gases...etc. Hence building an acoustic model for the DPF is necessary for the assessment of the diesel engine performance.

The performance of a DPF has been the subject of many theoretical and experimental studies over the last two decades. Greevesm [7] studied the origin of hydrocarbons emission from diesel engines and he found that DPF can eliminate some of PM and it is very promising as an after-treatment technique. Yu and Shahed [8] studied the effects of injection timing and exhaust gas recirculation on emissions from a diesel engine and they classified DPF as filtration and regenerative technique.

Konstandopoulous et al. [9] studied the wall-flow diesel particulate filters pressure drop and coolant efficiency and described the coupling between neighboring channels using Daracy's law to model flow through a porous medium. Peal [10] made an approximation to the effect of mean flow on sound propagation in capillary tubes. Astley and Cumings [11] presented FEM solutions, based on simplified equations for waves in a visco-thermal fluid, for the problem of sound propagation in capillary tubes. They made analysis for the laminar flow with a parabolic velocity distribution and a quadratic cross-section. The simplification of the governing equations is based on that the axial gradients are much smaller than the gradients over the cross-section [12].

Many techniques used for noise control in machines and automobiles such as:

\section{A. Damping}

Typical applications : Chutes, hoppers, machine guards, panels, conveyors, tanks .

There are 2 basic techniques:-

1) Unconstrained layer damping where a layer of bitumastic (or similar) high damping material is stuck to the surface

2) Constrained layer damping where a laminate is constructed

Constrained layer damping is more rugged and generally more effective. Either remanufacture steel (or aluminum) guards, panels or other components from commercially available sound deadened steel or buy self adhesive steel sheet. The latter can simply be stuck on to existing components (inside or outside) covering about $80 \%$ of the flat surface area to give a $5-25 \mathrm{~dB}$ reduction in the noise radiated (use a thickness that is $40 \%$ to $100 \%$ of the thickness of the panel to be treated).

\section{B. Pneumatic Nozzles}

Typical applications: Cooling, drying, blowing .

In most cases, it is possible to replace existing nozzles (usually simple copper pipe outlets) for quiet, high efficiency units. These not only reduce noise levels by up to $10 \mathrm{~dB}$, but also use less compressed air. The types of nozzle to look out for are entraining units (schematic below) from various manufacturers and in a variety of sizes. Fig. 3.

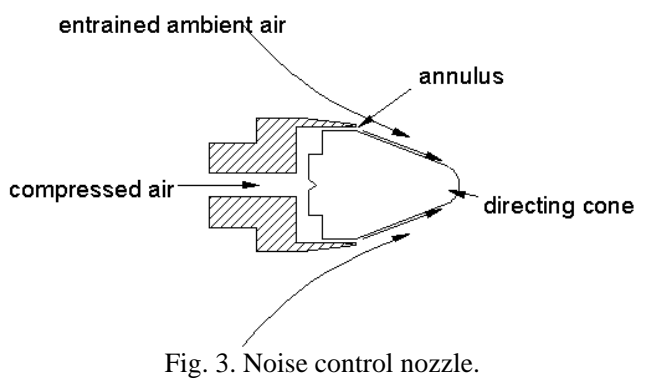

\section{Acoustic Absorbent}

Lining a significant proportion of the inside of the guards with acoustic absorbent (foam, rock-wool/ fiberglass) will reduce the noise "trapped" by the guards. Consequently, less noise will escape through any gaps. Failure to line the inside of the guards could result in an increase in noise at the operator's position if the gaps have been minimized [13]

\section{Chain and Timing Belt Drives}

Noisy chain drives can often be replaced directly with quieter timing belts. Within the range of timing belts available, there are also quiet designs that use different tooth profiles to minimize noise. There is also a very new design of belt for applications where noise is critical which uses a chevron tooth pattern to provide very quiet running. Noise reductions in the range of $6 .-20 \mathrm{~dB}$ are often possible using this approach.

\section{E. Electric Motors}

Most companies have large numbers of electric motors used on anything from fans to pumps to machine tools. However, it is not very common knowledge that general duty motors are available (at little or no cost premium) that are up to $10 \mathrm{~dB}(\mathrm{~A})$ or more quieter than typical units as direct replacements. The best approach is to feed these motors into the system over a period of time so that all replacement motors are quiet motors[3], [4] and [14]-[16].

Noise can often lead to reduced productivity in the workplace and sleep deprivation in the home. If the noise persists, it may cause stress and other adverse health effects. If untreated, high levels of noise can lead to permanent hearing damage. Barrier performance can be expressed in $\mathrm{dB}$ and is called the 'Transmission Loss' or 'Sound Reduction Index' denoted by TL and is defined as follows: 


$$
T L=10 \log (E i / E t)
$$

where: $E i$ : is the incident sound energy, Et: is the transmitted sound energy [5], [13]-[15], [17].

The control system block diagram that is shown in Fig. 4 below the input of the control circuit is the engine sound which can be step input, parabola, or ramp or any other types. The controller here is the DPF which has many control parameters like the porosity percent, the number of cells, permeability and others, the gain of the controller (depending on [5] and [6]) is designated as $G_{p d f}$ which can be written as:

$$
G_{p d f}=\varphi L / A
$$

where $\Phi$ : is the porosity of the DPF, $L$ : is the nominal length of the DPF, A: is the internal area of the filter.

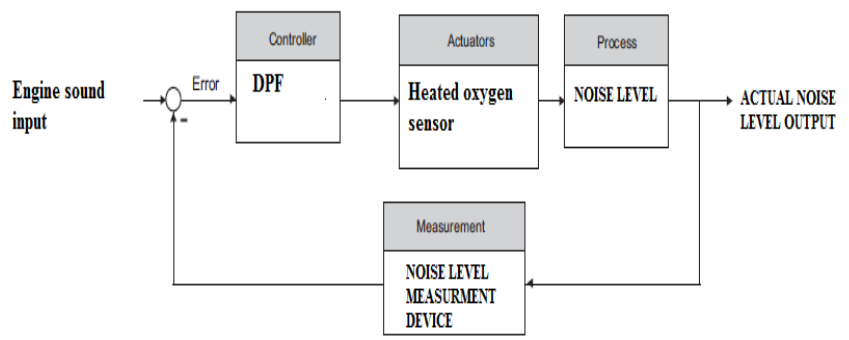

Fig. 4. Noise control system block diagram.

The controller connects with the actuator which is considered here as the heated oxygen sensor which controls the air- fuel ratio by communicating with the electronic control unit in the car. The aim of this paper is to construct what is called the transfer function, which can be defined as the actual noise level $(Y(s))$ to the desired noise level $(R(s))$ or

$$
T(s)=Y(s) / R(s)
$$

\section{RESULTS AND DISCUSSION}

The transfer function of the last diagram can be calculated by taking the forward path gain as: $G_{p d f}=\varphi L / A$, the backward gain can be considered as: s, so

$$
\begin{aligned}
T(s)=\frac{Y(s)}{R(s)} & =\frac{G(s)}{1+G(s) H(s)} \\
& =\frac{\varphi L / A}{1+[\varphi L / A] s}
\end{aligned}
$$

This yields to

$$
Y(s)=\frac{\varphi L / A}{1+[\varphi L / A] s} R(s)
$$

To find the response of the control system (which depends mainly on the input signal) which represents the actual level of the noise:

For step input noise: $R(\mathrm{~s})=1 / \mathrm{s}$

$$
y(t)=\mathrm{L}^{-1}(Y(s))=\mathrm{L}^{-1}\left[\frac{\varphi \mathrm{L} / \mathrm{A}}{1+[\varphi \mathrm{L} / \mathrm{A}] s} \times \frac{1}{s}\right]
$$

Yields, depending on Laplace inversion tables:

$$
y(t)=\frac{1}{2} e^{-\frac{1}{2 G_{d p f}} t} \sinh \frac{1}{2 G_{d p f}} t
$$

This response can be calculated and represented as a function of time as shown in Fig. 5. It can be noticed that the noise level increases up to some maximum value then stable, this value is known as the steady state response i.e. the noise can be controlled by using the DPF.

Fig. 6 shows the transmission losses for different types of DPFs as a relation with the frequency of the engine input sound tension at hot condions.

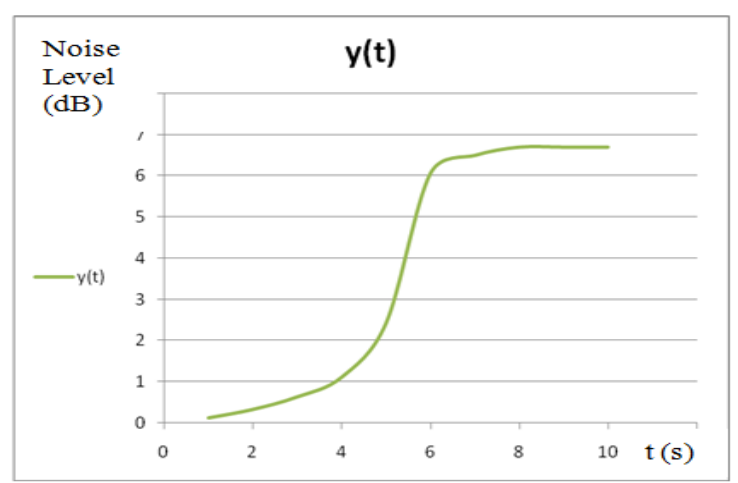

Fig. 5. Response of the control system-noise level.

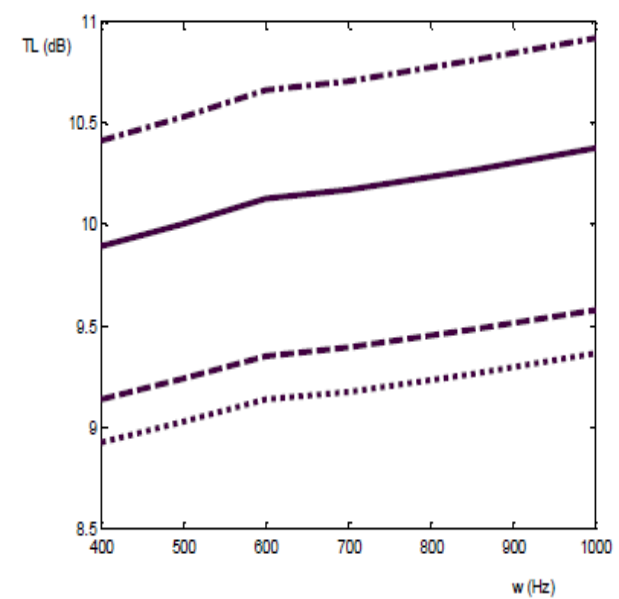

Fig. 6. Transmission losses vs. frequency, __ for RC:200/12,-.-.-.for EX80:200/14, -----for EX80:100/17, and.....for RC: 200/20 DPF unit type in the case of hot conditions, (With soot layer). $\mathrm{Mach}=0.02 .[5]$, and [17].

\section{CONCLUSIONS}

Noise really causes many healthy and un-comfort for humans, one of the leading and promising devices is the diesel particulate filter, in addition to its role in emission reduction it can make noise reduction, the control system of noise using DPF is constructed and the control systems' transfer function is derived. The time response shows that the noise can be damped and reaches the steady state case within some given time, the transmission losses that DPF can perform is considerable, the main parameters controlling DPF operation are its dimensions and porosity.

\section{REFERENCES}

[1] National Clean Diesel Campaign report, Diesel Particulate Filter General Information, EPA-420-F-10-029, May, 2010. 
[2] F. O. X. Be cota, L. Jaouenb, and F. Sgard, "Noise control strategies using composite porous materials Simulations and experimental validations on plate/cavity systems," Noise Control Eng. J., vol. 59, no. 5, September-October, 2011.

[3] X. Olny and C. Boutin, "Acoustic wave propagation in double porosity media," J. Acoust. Soc. Am., vol. 114, pp. 73-89, 2003.

[4] E. Gourdon and M. Seppi, "On the use of porous inclusions to improve the acoustical response of porous materials: Analytical model and experimental verification," Applied Acoustics, vol. 71, no. 4, pp 283-298, 2010.

[5] S. M. Fayyad, M. N. Hamadn, M. A. Hamdan, "Sound propagation in porous media, with applications to DPF," Ph.D. Dissertation, Mechanical Eng. Dept., university of Jordan. 2009.

[6] S. Allam and S. M. Abom, "Sound propagation in an array of narrow porous channels with application to diesel particulate filters," Journal of Sound and Vibration, vol. 291, pp. 882-901, 2006.

[7] G. Greevesm, I. M. Khan, C. H. T. Wang, and I. Fenne, "Origins of hydrocarbon emission from diesel engines," Society of Automotive Engineering, SAE Paper, no. 770259, pp. 02-01, 1977.

[8] R. Yu and S. M. Shahed, "Effects of injection timing and exhaust gas recirculation on emissions from a DI diesel engine," Society of Automotive Engineering, SAE Paper, no. 811234, 1981.

[9] G. Konstandopoulos and J. H. Johnson, "Wall-flow diesel particulate filters - their pressure drop and collection efficiency," Society of Automotive Engineering, SAE Paper, no. 890405, 1989.

[10] K. S. Peat, "A first approximation to the effects of mean flow on sound propagation in capillary tubes," Journal of Sound and Vibration, vol. 175, pp. 475-489, 1994.

[11] R. J. Astley and A. Cummings, "Wave propagation in catalytic converter formulation of the problem and finite element scheme," Journal of Sound and vibration, vol. 188, no. 5, pp. 635-657, 1995.
[12] E. Dokumaci, "Sound transmission in narrow pipes with superimposed uniform mean flow and acoustic modeling of automobile catalytic converters," Journal of Sound and Vibration, vol. 182, pp. 799-808, 1995.

[13] J. G. Ih, C. M. Park, and H. J. Kim, "A model for sound propagation in capillary ducts with mean flow," Journal of Sound and Vibration, vol. 190, no. 2, pp. 163-175, 1996.

[14] K. W. Joeng and J. G. Ih, "A numerical study on the propagation of sound through capillary tubes with mean flow," Journal of Sound and Vibration, vol. 198, no. 1, pp. 67-79, 1996.

[15] E. Dokumaci, "On transmission of sound in circular and rectangular narrow pipes with superimposed mean flow," Journal of sound and vibration, vol. 210, no. 3, 1998, pp. 375-389.

[16] E. Dokumaci, "An approximate dispersion equation for sound waves in a narrow pipe with ambient gradients," Journal of Sound and Vibration, vol. 240, no. 4, pp. 637-646, 2001.

[17] S. Allam and S. M. Abom, "Acoustic modeling and testing of diesel particulate filters," Journal of Sound and Vibration, vol. 288, no. 1/2, pp. 255-273, 2005.

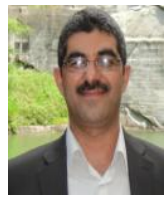

Sayel M. Fayyad is a professor assistant, mechanical Engineering Department, Al-Balqa' Applied University, Faculty of Engineering Technology, Amman, Jordan. 